\title{
MicroRNA profiling of novel African American and Caucasian Prostate Cancer cell lines reveals a reciprocal regulatory relationship of miR-152 and DNA methyltranferase 1
}

\author{
Shaniece C. Theodore ${ }^{1}$, Melissa Davis ${ }^{3}$, Fu Zhao ${ }^{1}$, Honghe Wang ${ }^{1}$, Dongquan Chen ${ }^{6}$, \\ Johng Rhim ${ }^{2}$, Windy Dean-Colomb ${ }^{7}$, Timothy Turner ${ }^{1}$, Weidong Ji ${ }^{5}$, Guohua Zeng \\ 5, William Grizzle ${ }^{4}$, Clayton Yates ${ }^{1}$ \\ ${ }^{1}$ Department of Biology and Center for Cancer Research, Tuskegee University, Tuskegee, AL \\ ${ }^{2}$ Center for Prostate Disease Research, Department of Surgery, Uniformed Services University of the Health Sciences, \\ Bethesda, MD \\ ${ }^{3}$ Department of Genetics, University of Georgia, Athens, GA \\ ${ }^{4}$ Department of Pathology, University of Alabama at Birmingham School of Medicine, Birmingham, AL \\ ${ }^{5}$ Department of Urology, Minimally Invasive Surgery Center, The First Affiliated Hospital of Guangzhou Medical College, \\ Guangdong Provincial Key Laboratory of Urology, 1 Kangda Road, Guangzhou 510230, China \\ ${ }^{6}$ Division of Preventive Medicine, University of Alabama at Birmingham School of Medicine, Birmingham, AL \\ 7 Department of Oncologic Sciences, University of South Alabama Mitchell Cancer Institute, Mobile, AL \\ Correspondence to: Clayton Yates, email: cyates@mytu.tuskegee.edu
}

Keywords: miRNA, DNA methylation, African American, prostate cancer

Received: April 9, $2014 \quad$ Accepted: May 7, $2014 \quad$ Published: May 8, 2014

This is an open-access article distributed under the terms of the Creative Commons Attribution License, which permits unrestricted use, distribution, and reproduction in any medium, provided the original author and source are credited.

\section{ABSTRACT}

miRNA expression in African American compared to Caucasian PCa patients has not been widely explored. Herein, we probed the miRNA expression profile of novel AA and CA derived prostate cancer cell lines. We found a unique miRNA signature associated with AA cell lines, independent of tumor status. Evaluation of the most differentially expressed miRNAs showed that miR-132, miR-367b, miR-410, and miR152 were decreased in more aggressive cells, and this was reversed after treatment of the cells with 5-aza-2'-deoxycytidine. Sequencing of the miR-152 promoter confirmed that it was highly methylated. Ectopic expression of miR-152 resulted in decreased growth, migration, and invasion. Informatics analysis of a large patient cohort showed that decreased miR-152 expression correlated with increased metastasis and a decrease in biochemical recurrence free survival. Analysis of 39 prostate cancer tissues with matched controls ( 20 AA and 19 CA), showed that $50 \%$ of AA patients had statistically significant lower miR-152 expression compared to only $35 \%$ of $C A$ patients. Ectopic expression of miR-152 in LNCaP, PC-3, and MDA-PCa-2b cells downregulated DNA (cytosine-5)-methyltransferase 1 (DNMT1) through direct binding in the DNMT1 3'UTR. There appeared to be a reciprocal regulatory relationship of miR152/DNMT1 expression, as cells treated with siRNA DNMT1 caused miR-152 to be re-expressed in all cell lines. In summary, these results demonstrate that epigenetic regulation of miR-152/DNMT1 may play an important role in multiple events that contribute to the aggressiveness of PCa tumors, with an emphasis on AA PCa patients .

\section{INTRODUCTION}

The most commonly diagnosed type of cancer among men in the US is prostate cancer (PCa), which accounts for $29 \%(241,740)$ of all new cancer cases.
Although the number of new cases of PCa has decreased in recent years, there are still racial and ethnic differences in PCa epidemiology. African-Americans (AAs) have the world's highest incidence of $\mathrm{PCa}$ and more than twofold higher mortality rate compared with Caucasian Americans 
(CAs) [1]. Overall, AA patients are younger and have higher Gleason scores, PSA levels, and incidence of palpable disease [2]. Various factors have been associated with the more aggressive prostate tumors. For example, differential gene expression in AA patients contributes to aggressive disease [3-7], and epigenetic mechanisms, such as DNA methylation, result in the loss of key regulatory genes $[8,9]$. This is particularly evident for AA patients where hypermethylation of genes in normal or premalignant areas are thought to predispose to malignancy $[10,11]$. However, the underlying mechanism of these acquired methylation patterns is poorly understood.

MicroRNAs (miRNAs) are small RNA molecules consisting of 19-23 nucleotides that regulate various biological processes. More than $60 \%$ of protein-coding genes may be targeted by miRNAs [12], mainly through translational repression and degradation of target mRNAs. An expanding body of evidence supports a role for miRNAs in disease progression and the potential for epigenetic mechanisms, such as DNA methylation, to regulate miRNA expression $[13,14]$. Recently, DNA methylation of proximal $\mathrm{CpG}$ islands in miRNA promoters was described as a method for decreased expression in various cancers, including PCas [15-18]. Although miRNAs are expressed differently in healthy tissues and cancers [19] and in localized and advanced tumors [20], little is known about racial differences in miRNA expression. Identification of unique miRNAs and mRNAassociated targets will begin to clarify the specific events involved in the progression of PCas in AAs.

To address this question, our laboratory has established non-malignant and malignant cell lines derived from AA PCas that replicate many of the clinical features of the original PCas [21, 22]. Thus, utilizing these cell lines and commonly available PCa cell lines, we explored the possibility of race-related differences in miRNA expression. Herein, we report that AA cell lines have a distinct miRNA signature, independent of tumor status. Evaluation of the miRNAs most differentially expressed demonstrated that miR-132, miR-367b, miR410 , and miR-152 were decreased in more aggressive cells and that this expression was reversed after treatment of the cells with 5-aza-2'-deoxycytidine (5-aza-2'd). Bisulfite conversion and sequencing of the promoter showed that miR-152 was highly methylated in LNCaP and PC-3 cells. Ectopic expression of miR-152 resulted in decreased cell proliferation, migration, and invasion. In a panel of $39 \mathrm{PCa}$ tumors with adjacent matched controls (20 AA and $19 \mathrm{CA}$ ), $50 \%$ of AA patients and $35 \%$ of CA patients demonstrated statistically significant lower miR152 expression compared to adjacent controls. Ectopic expression of miR-152 down-regulated DNA(cytosine5)-methyltransferase 1 (DNMT1) through direct binding in the DNMT1 3'UTR. This appeared to be an inverse relationship, as cells treated with DNMT1 siRNA reexpressed miR-152. Finally, as determined with a large patient cohort, loss of miR-152 was related to poor clinical outcomes including decreased biochemical recurrent free survival.

\section{RESULTS}

\section{miRNA Profile of Panel of AA and CA Cell Lines}

To determine the miRNA expression pattern in our panel of AA and CA prostate cell lines, the expression of 662 miRNAs was analyzed utilizing Asuragen Affymetrix Gene Chips. To validate the malignant and nonmalignant status of this cell line panel, we first preformed hierarchical clustering (Figure 1a) and a PLS plot (Figure $1 b)$, using reported non-malignant and malignant status as the grouping criteria. Both analysis demonstrated distinct expression patterns in the malignant and non-malignant cell lines, with 21 differentially expressed miRNAs between the groups (Supplemental Table $1(\mathrm{p}<0.00001)$. To further determine race related miRNAs, we performed a separate hierarchical clustering analysis on the same data set utilizing racial background as the grouping criteria. Distinct hierarchical clustering of miRNAs was evident between the AA and CA cell lines (Figure 1c), regardless of malignancy status. A PLS plot reflected this pattern, with distinct variations in the racial profiles of the AA and CA cell lines (Figure 1d). In this variation, there were 47 miRNAs differentially expressed by race (Supplemental Table 2). To confirm these 47 miRNAs are race related, we interrogated a microarray dataset that consisted of primary tumor cells isolated from $5 \mathrm{AA}$ and $4 \mathrm{CA}$ patients (Supplemental Table 3). These race related miRNA probes were able to differentiate patients relevant to race using PLS plot test (Supplemental Figure 1).

To determine if these miRNA's have a relationship to prostate cancer progression, we took the most significantly differentially expressed race related miRNA's $(p<0.00001)$ (Table 1), and performed qRT-PCR validation within our prostate cancer cell line progression model. Of the 11 miRNAs, we confirmed the 5 most significant by qRTPCR in non-malignant and selected aggressive malignant cell lines (Supplementary Figure 2). With the exception of miR-363, which did not exhibit a clear expression pattern, miR-132, miR-376b, miR-410 and miR-152 exhibited a decreased expression profile as the metastatic capability of cell lines increased. Thus, we chose these miRNAs for further analysis.

\section{Demethylation Treatment Reverses miRNA Expression of AA-Associated miRNAs.}

Previous reports and in silico analyses have demonstrated that a majority of the miRNAs we found associated with race contain $\mathrm{CpG}$ islands within the 


\begin{tabular}{|l|l|}
\hline \multicolumn{2}{|l|}{$\begin{array}{l}\text { Table 1: Hierarchical clustering of race related } \\
\text { miRNAs }\end{array}$} \\
\hline miRNA & (Adjusted) p-value $\uparrow$ \\
\hline hsa-miR-363 & $3.43 \mathrm{e}-05$ \\
\hline hsa-miR-132 & 0.000354 \\
\hline hsa-miR-376b & 0.00188 \\
\hline hsa-miR-410 & 0.00291 \\
\hline hsa-miR-152 & 0.00471 \\
\hline hsa-miR-189 & 0.00498 \\
\hline hsa-miR110 & 0.00514 \\
\hline hsa-miR-27b & 0.00657 \\
\hline hsa-miR-519c & 0.0071 \\
\hline hsa-miR-520h & 0.00774 \\
\hline hsa-miR-27a & 0.00837 \\
\hline **miRNAs separated by race are listed based on p-value \\
\hline
\end{tabular}

promoter regions upstream of the start site (Supplemental Figure 3). To determine if hypermethylation is associated with decreased expression of these miRNAs, LNCaP and PC-3 cells were treated with $5 \mu \mathrm{M}$ 5-aza-2'd alone for three days or in combination with $100 \mathrm{nM}$ TSA for $24 \mathrm{hr}$. Re-expression of multiple miRNAs was evident in both LNCaP and PC-3 cells after 5-aza-2'd treatment. However, miR-376b and miR-152 showed the most substantial increases in both cell lines (Figure 2).

Since miR-152 contained the greatest percentage of methylated CG sequences and demonstrated the most consistent increases after 5-aza-2'd treatment, we focused on this miRNA. To determine the methylation status of the miR-152 promoter region, we extracted DNA from LNCaP and PC-3 cell lines and performed sodium bisulfite modification prior to sequencing. To confirm these results, sodium bisulfite-converted DNA was subjected to capillary electrophoresis and analyzed utilizing the online Bisulfite Sequencing DNA Methylation Analysis (BISMA) sequencing program. The results indicated that DNA of both LNCaP and PC-3 cell lines was 100\% methylated at 1000 base pairs upstream from the promoter region (Figure 3). Thus, these results suggest that in malignant PCa cell lines, miR-152 is inactivated through hypermethylation.

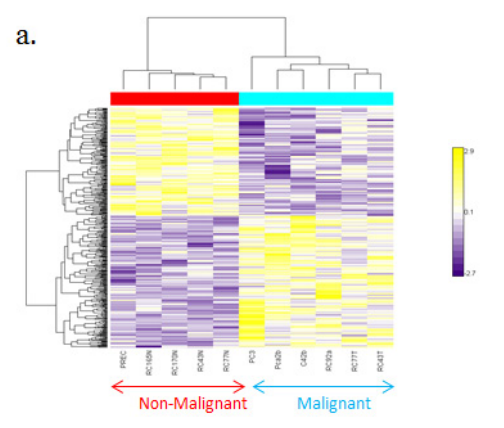

b.
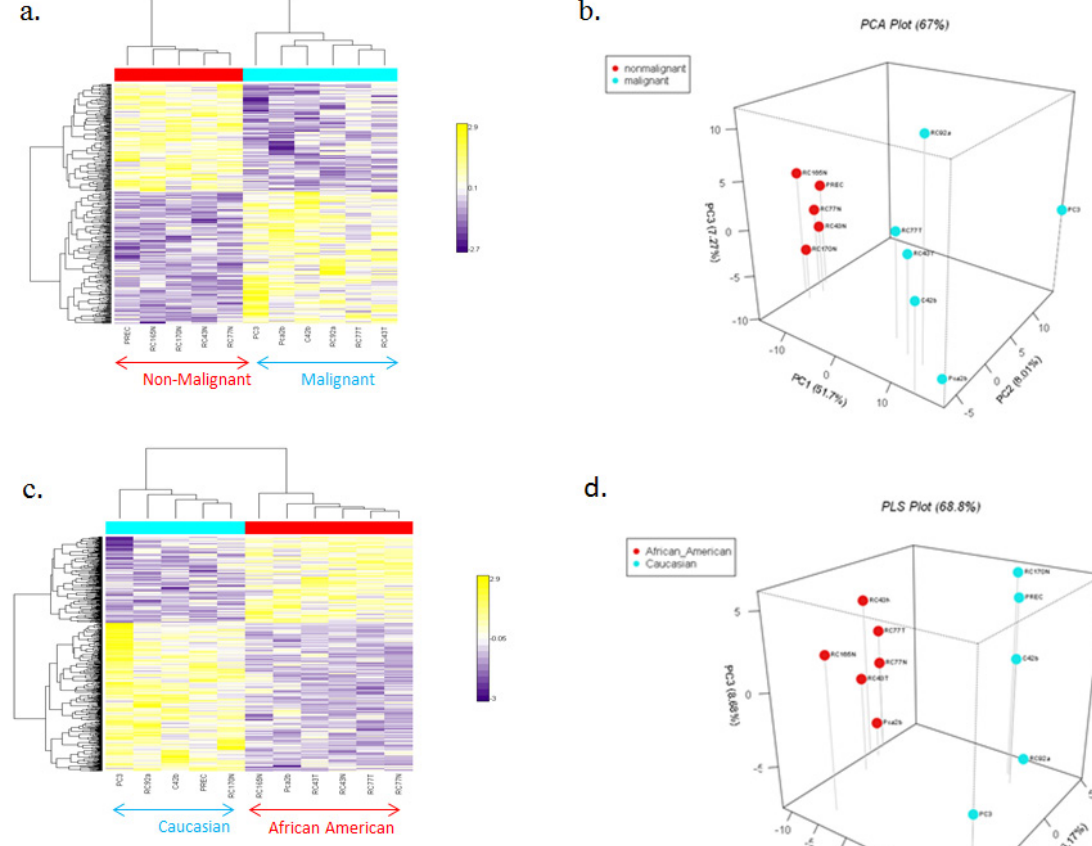

d.

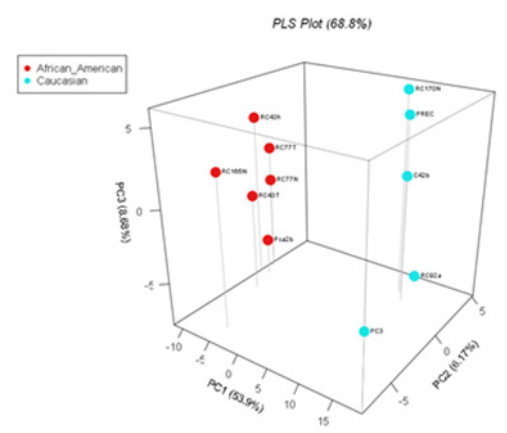

Fig. 1: Heat Map of miRNA microarray. (a) Hierarchical clustering analyses of miRNAs (left) grouped by non-malignant and malignant status: non-malignant cell lines (red block), malignant cell lines (blue block). (b) PLS plot of AA and CA prostate cell lines grouped by malignancy. (c) Hierarchical clustering analyses of miRNAs (left) grouped by race. AA cell lines (red block), CA cell lines (blue block). miRNAs are ordered according to their cluster determined by p-values using the Kruskal-Walis test. (d) PLS plot of AA and CA prostate cell lines grouped by race. 


\section{miR-152 Expression Correlates with Clinical and Pathological Variables.}

a.

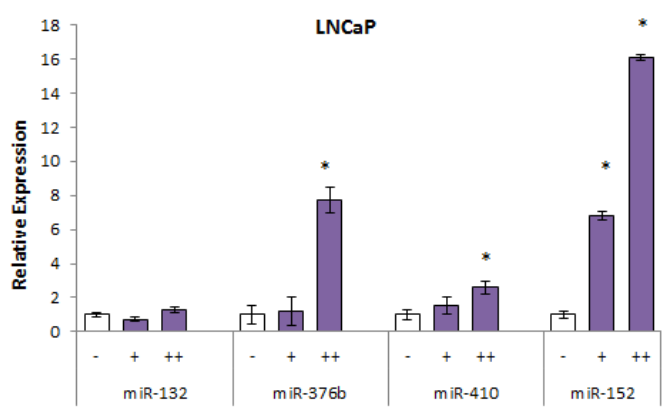

b.

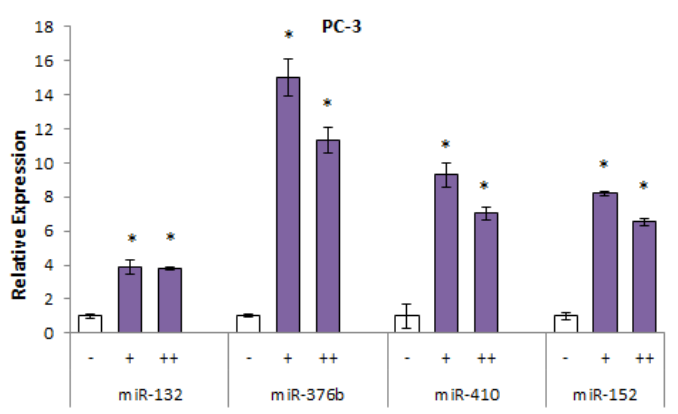

Fig. 2: Multiple miRNA expression pattern after treatment with demethylation agent (a) LNCaP cells were treated with 5 $\mu \mathrm{M}$ 5-aza-2'd for 4 days alone (+) or with $100 \mathrm{nM}$ TSA for 24 $\mathrm{hr}(++)$. Results shown are representative of three independent experiments \pm s.e. $* \mathrm{P}<0.05$. (b) $\mathrm{PC}-3$ cells were treated with $5 \mu \mathrm{M}$ 5-aza-2'd for 4 days alone (+) or with $100 \mathrm{nM}$ TSA for 24 hours $(++)$. Results shown are representative of three independent experiments \pm s.e. ${ }^{*} \mathrm{P}<0.05$.
The expression of miR-152 in 28 normal cell lines, 97 primary tumors, and 13 metastases was analyzed using the Taylor et al. GSE21032 data set available on the GEO website (http://www.ncbi.nlm.nih.gov/geo/). Primary and metastatic tumors had lower levels of miR-152 relative to normal samples (Figure 4a), which correlated with the higher incidence of metastatic samples, metastatic events, and lymph node invasion (Figures $4 \mathrm{~b}$ and c). Tumors with low miR-152 levels also had reduced biochemical recurrence-free survival (Figure 4c). Together, this describes a consistent picture of low miR-152 levels associated with PCa metastasis and recurrence.

These results prompted us to determine miR152 expression in our patient cohort of AAs and CAs, hypothesizing that tumors from AAs would have lower miR-152 than those from CA patients. Patients were selected based on cancers of higher total Gleason score ( $\geq 6$ ) and/or pathological stage (pT2), and positive for perineural and/or vascular invasion, as these pathological characteristics correlate positively with tumor aggressiveness and metastasis. AA patients had a lower median age relative to similarly staged CA patients, which was also associated with lower miR-152 levels measured by qRT-PCR (Table 2, p<.001). Analysis of miR-152 expression in individual tumors compared to matching adjacent normal controls showed a statistically significant decrease in miR-152 expression in 50\% of the AA patients compared to only $35 \%$ of CA patients (Figure 5a, b Supplemental table 4).

a.
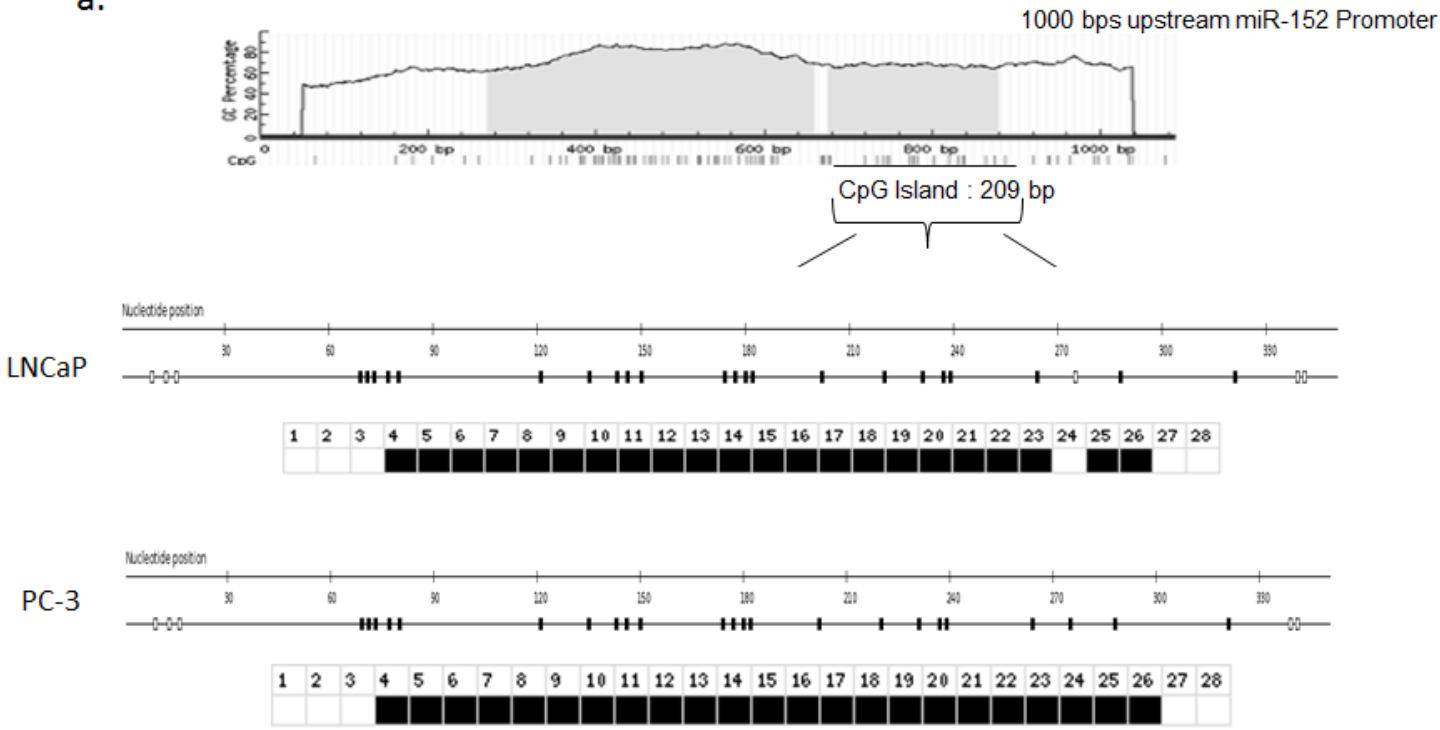

Fig. 3: Bisulfite Sequencing of CpG islands in the miR-152 promoter. (a) Schematic map of the CpG islands in the miR-152 promoter using UCSC Genome Browser. CpG islands are indicated as vertical lines on map. (b) Bisulfite modification was performed on LNCaP and PC-3 cells, and DNA was sequenced to determine the methylation status of the promoter region. Bisulfite sequencing was analyzed by BDPC software (see Methods). Open square; unmethylated CpG; closed square, methylated CpG. 


\begin{tabular}{|c|c|c|c|}
\hline Ethnicity & African American & Caucasian & $\mathrm{p} \dagger$ \\
\hline Samples & $20(51.3 \%)$ & $19(48.7 \%)$ & \\
\hline \multicolumn{4}{|l|}{ Age } \\
\hline Median & 57.5 & 64 & \\
\hline Mean & 57.3 & 60 & \\
\hline Standard deviation & 6.68 & 7.3 & \\
\hline Min - Max & $47-69$ & $48-70$ & \\
\hline \multicolumn{4}{|l|}{ Initial Clinical Stage } \\
\hline $\mathrm{T} 1$ & NA & NA & \\
\hline $\mathrm{T} 2$ & $16(80 \%)$ & $10(52.6 \%)$ & \\
\hline $\mathrm{T} 3$ & $4(20 \%)$ & $8(42.1 \%)$ & \\
\hline NS & NA & $1(5.3 \%)$ & \\
\hline \multicolumn{4}{|l|}{ Gleason Score } \\
\hline 6 & $8(40 \%)$ & $8(42.1 \%)$ & \\
\hline 7 & $12(60 \%)$ & $10(52.6 \%)$ & \\
\hline 8 & NA & $1(5.26)$ & \\
\hline \multicolumn{4}{|l|}{ miR-152 Expression } \\
\hline $\begin{array}{l}\text { Average All Samples } \\
\pm \text { SD }\end{array}$ & $1.6 \pm$ & $2.6 \pm$ & $\mathrm{p}<.001^{\star}$ \\
\hline \multicolumn{4}{|c|}{$\begin{array}{l}\dagger \mathrm{P} \text { value with }{ }^{\star} \text { is deemed significant utilizing F- test } \\
\text { NA- none } \\
\text { SD- Standard Deviation }\end{array}$} \\
\hline
\end{tabular}

\section{Restoring miR-152 Expression Decreases Cell Growth.}

The clinical relevance of miR-152 in PCa prompted us to determine if loss of expression had a biological or functional role in promoting metastatic tumors. After optimizing the concentration of miR-152 mimics that restored miR-152, miR-152 was transfected into LNCaP, PC-3, and MDA-PCa-2b cells. As determined by MTT assays, ectopic expression of miR-152 inhibited cell proliferation after 3 days, and this continued to Day 6 (Figure $6 \mathrm{a}, \mathrm{b}, \mathrm{c}$ ). Since the inhibition of cell proliferation began at $72 \mathrm{hr}$, miR-152 transfected cells were next assayed after $72 \mathrm{hr}$ by flow cytometry to determine if there was an effect on cell cycle progression. miR-152 treatment caused cells to accumulate at the G2-M phase (LNCaP NC 22.90\% compared to miR-152-transfected cells $30.2 \%$; PC-3 NC $19.9 \%$ vs miR-152 transfected cells 29.3\%; MDA-PCa-2b NC 33.15 vs miR-152 transfected cells $37.59 \%$ ) (Figure $6 \mathrm{~d}$, e, f). In addition to reduced cell proliferation, miR-152 transfected LNCaP, PC-3, and MDA-PCa-2b cells demonstrated a decrease in cell migration (Figure 6g) and invasion (Figure 6h).

Previously, miR-152 was demonstrated to target DNMT1 expression in endometrial tumors [23]. Since we observed that numerous miRNAs in our panel were influenced by methylation, and the methyltransferase DNMT1 is a regulator of DNA hypermethylation in various tumor types, we sought to explore the miR152/DNMT1 relationship in PCas. First, the relative expressions of DNMT1 and miR-152 were examined in our panel of cell lines. As expected, qRT-PCR showed that DNMT1 expression was elevated in the more aggressive cell lines, and this correlated with decreased expression of miR-152 (Figure 7a).

DNMT1 expression was then examined in LNCaP, PC-3, MDA-PCa-2b cells transfected with miR-152. Both types of cells showed statistically significant decreases in DNMT1 expression at the RNA and protein levels (Figure $7 \mathrm{~b}$ ). This relationship is possibly direct, as miR152 has putative binding sites in position 45-54 of the DNMT1 3' UTR. To confirm this, we utilized a previously established DNMT1 3'-UTR luciferase reporter system 
a.

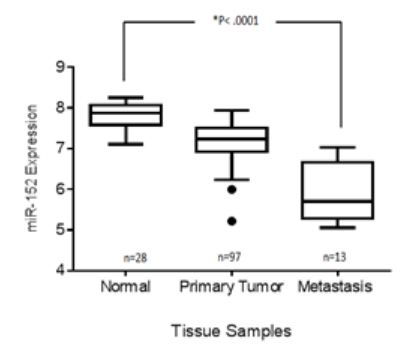

c.

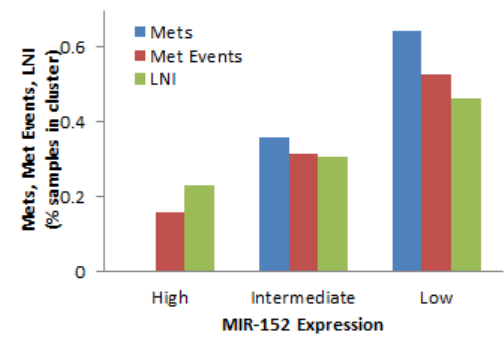

b.

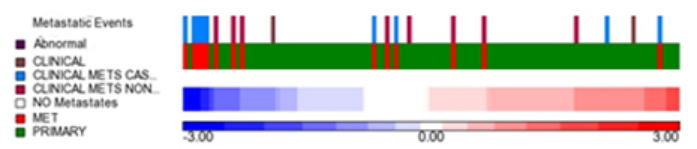

d.

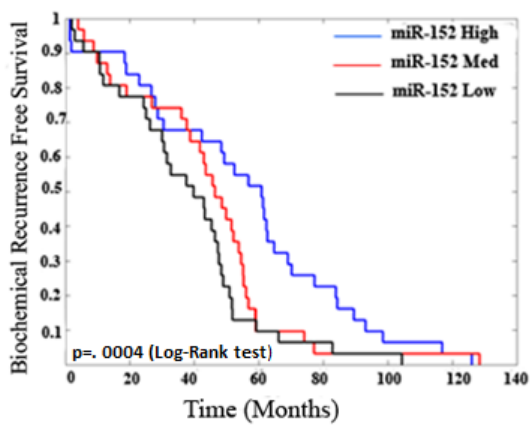

Fig. 4: Low miR-152 expression correlation with PCa metastasis. Taylor et al data set samples were sorted by average miR-152 expression and the mean from two probes was normalized with z-score. (a-d) miR-152 expression correlates with metastases, invasion events, and recurrence-free survival in $138 \mathrm{PCa}$ samples (97 primary tumors and 13 metastases). (a) miR-152 levels decrease monotonically from normal, primary tumor, and metastasis, $P<0.0001$. (b) Intensity in heatmap, with red corresponding to high and blue to low expression, with common event that occur in PCa metastasis. (c) Number of metastatic events separated by high, intermediate, and low miR-152 expression. (d) Low miR-152 expression correlated with decrease in probability of biochemical recurrence free survival $\mathrm{p}=0.0004$ (logrank test).

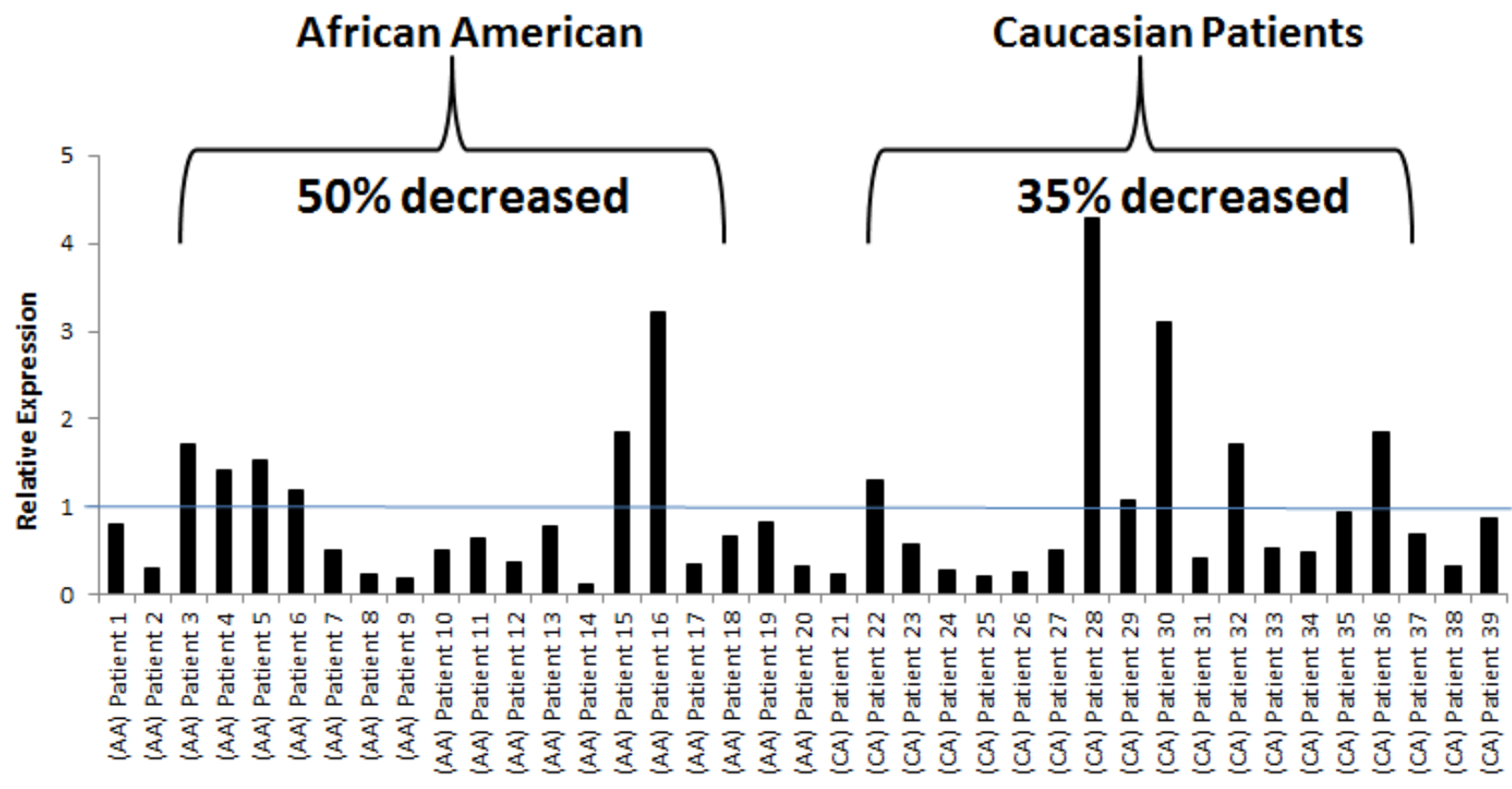

Tissue Samples

Fig 5: miR-152 expression in AA and CA matched normal tumor cohort. (a) qRT-PCR of miR-152 expression in normaltumor paired prostate tissue samples. All samples were normalized to the adjacent normal samples. All values under value one represent down-regulation of miR-152. (b) Plot demonstrating the individual miR-152 expression values in AA and CA patients: Note: $50 \%$ of the individual AA patients had significant lower miR-152 expression compared to only $35 \%$ of CA patients. p-values (Benjamini-Hochberg corrected for multiple tests) . 
[24] containing the miR-152-binding sites (DNMT1 wildtype 3'- UTR) or mutating these sites (DNMT1 Mu 3'UTR) that contain the putative miR-152 binding sites.
All miR-152 transfected cells showed decreased DNMT1 wild-type 3'-UTR luciferase activity, whereas DNMT1 $\mathrm{Mu}$ 3'-UTR luciferase activity was not affected (Figure

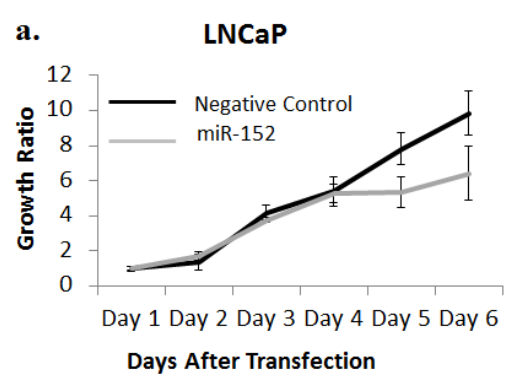

b.

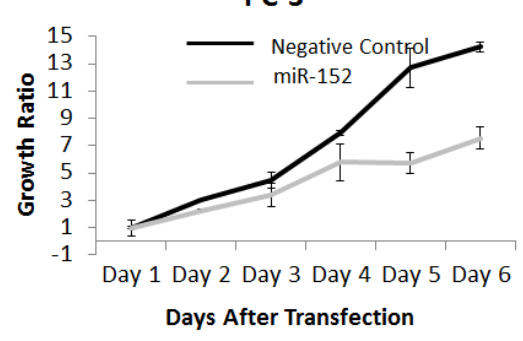

c.

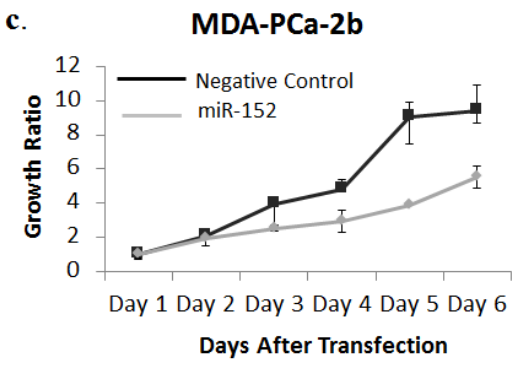

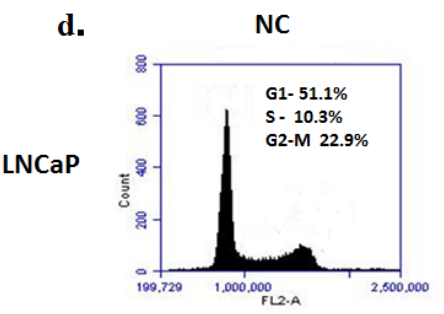
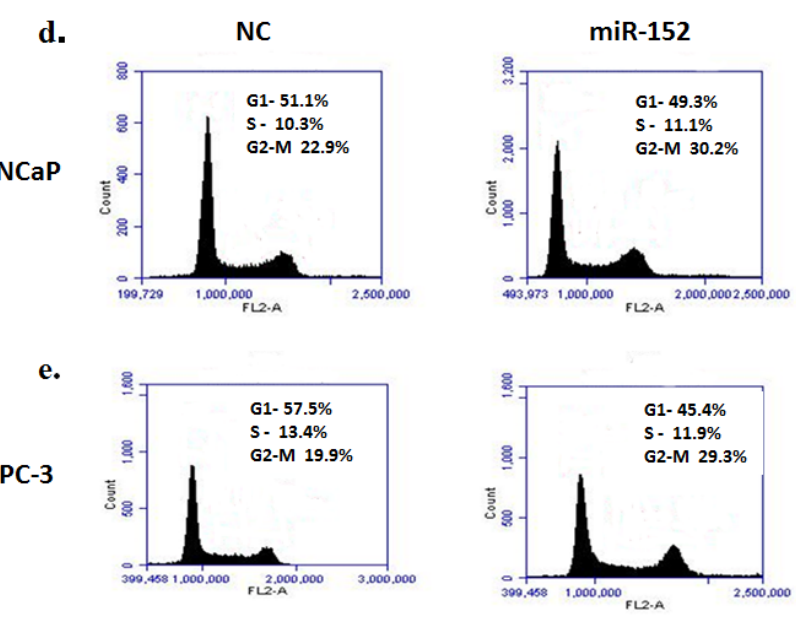

f.
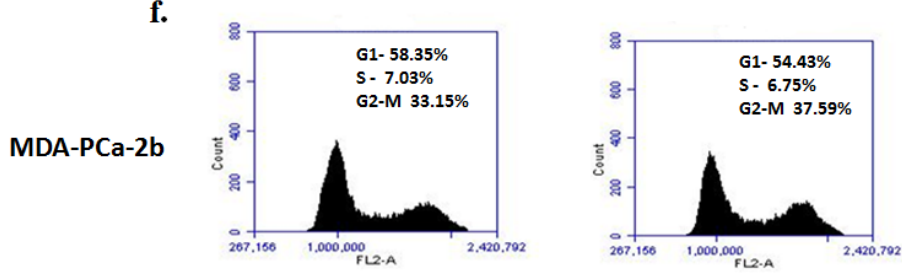

g..

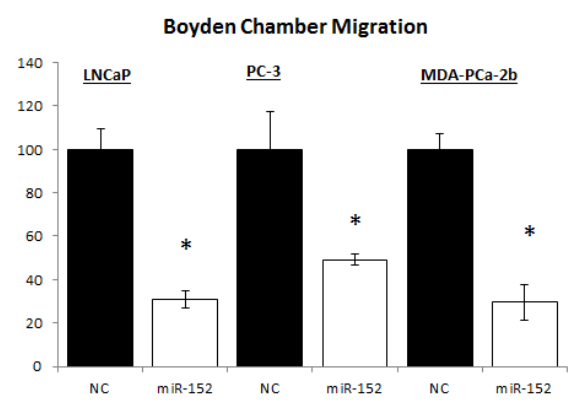

h.

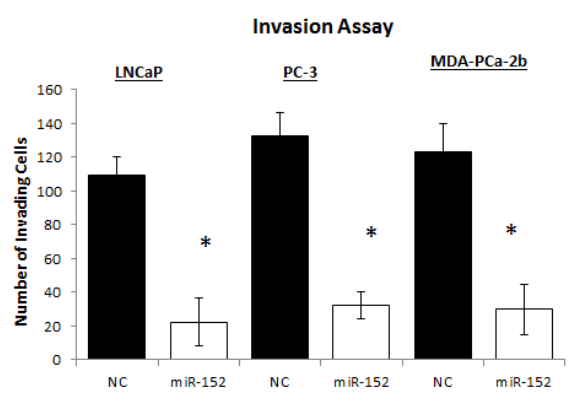

Fig 6: Restoring miR-152 expression decreases cell proliferation, migration, and invasion. (a) Proliferation of LNCaP, (b) PC-3, (c) and MDA-PCa2b cells that were transfected with either $30 \mathrm{nM}$ of miR-152 mimic or miR-NC (negative control) was measured by MTT for 6 days. Results shown are representative of three independent experiments averaged and normalized to Day $1 \pm$ s.e. ${ }^{*} \mathrm{p}<0.05$. (d) LNCaP, (e) PC-3, (f) and MDA-PCa-2b cells were analyzed by flow cytometry after 3 days of miR-152 mimic transfection (30 nM). miR-152 caused G2-M arrest in cell cycle progression in PCa cell lines. Results shown are representative of three independent experiments. (g) Relative cell migration of LNCaP PC-3, and MDA-PCa-2b cells was measured utilizing Boyden migration chambers. Results shown are representative of two individual experiments performed in triplicate. (h) LNCaP, PC-3, and MDA-PCa-2b cells transfected with miR152 mimic showed a decrease in the number of cells invading through a layer of Matrigel relative to cells treated with miR-NC (negative control). All data presented are the means of three independent experiments \pm s.e. ${ }^{*} \mathrm{P}<0.05$. 
7c). Since we demonstrated that loss of miR-152 occurs through promoter methylation, we asked if there was a reciprocal relationship between miR-152 and DNMT1. Treatment of LNCaP, PC-3, and MDA-PCa-2b cells with DNMT1 siRNA caused statistically significant increases in miR-152 expression (Figure 7d).

To examine the possible broader influence that loss of miR-152 has in PCas, we queried the TargetScan in silico database to determine additional gene targets that could be regulated by miR-152. Of the top genes, Rictor, TGF- $\beta$, SOS1, ABCD3, SMAD4, SOX2, E2F1, and Dicer were predicted. To determine their influence, a custom gene array of these genes was designed (Supplemental Table 5), and expression levels in LNCaP, PC-3, and MDA-PCa-2b cells that were transfected with miR-152 were assayed. Although, the effect of ectopic miR-152 on gene expression varied among the cell lines, we observed consistent decrease expression in Rictor, TGF- $\beta$, and SOS1. Interestingly, in the African American derived MDA-PCa-2b, we observed significant decreases in ABCD3 and SOS1, which have been previously reported to be associated with African American prostate tumors [4, 5]. Together, these results indicate that miR-152 regulates epigenetic events that promote tumorigenesis.

\section{DISCUSSION}

Numerous studies have now reported gene differences AA and CA prostate tumors [4, 6, 7, 25, 26]. As the field of health disparities is in its infancy, these reports provide the first evidence of population-based genetic contributions to aggressive disease. However, the regulation of these genes is still elusive. To address this question, without influence of non-epithelial a.

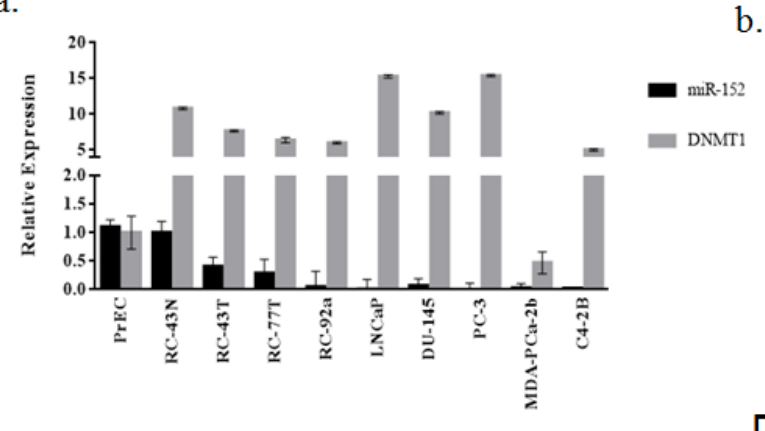

Cell Lines

c.

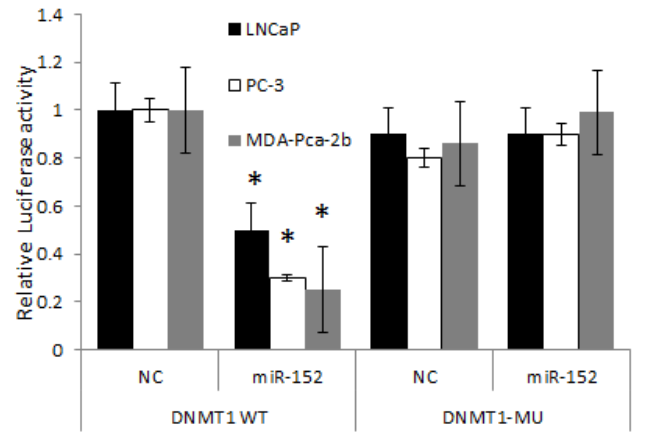

d. b.
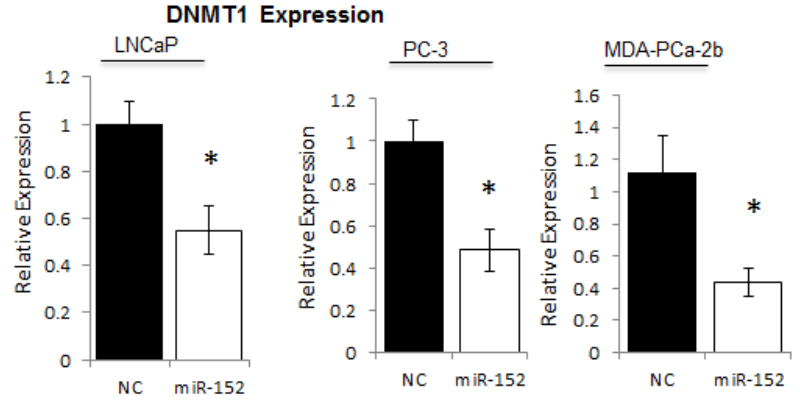

DNMT1

$\beta$-actin
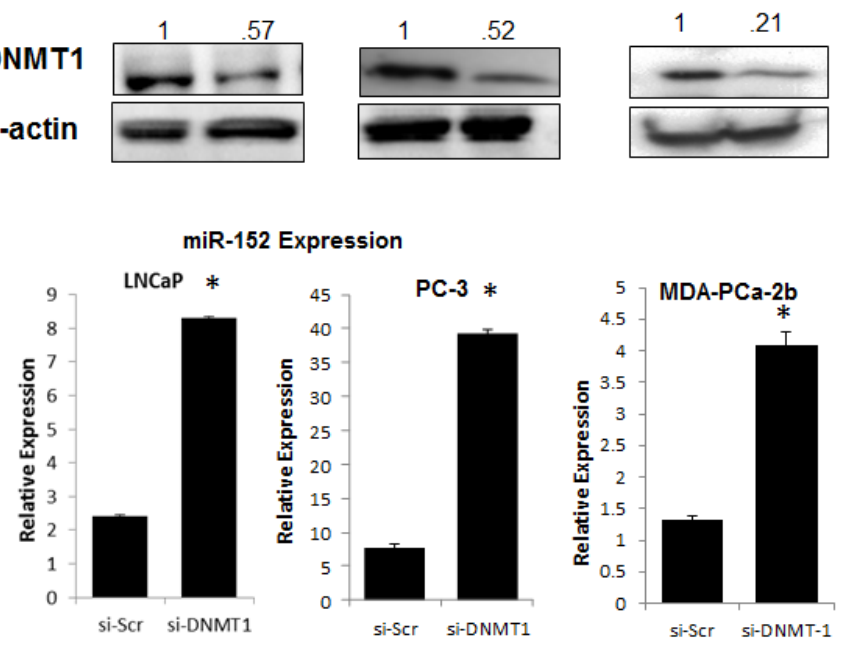

si-DNMT1

$\beta$-actin
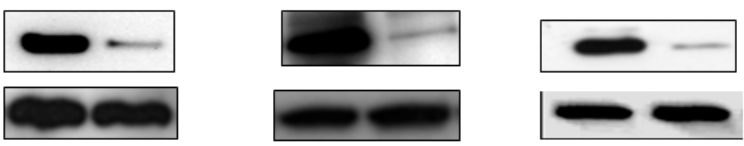

Fig. 7: Comparison of miR-152 and DNMT-1 relationship in PCa cell lines (a) Relative miRNA and mRNA expressions of miR-152 and DNMT1 were determined by qRT-PCR in a panel of prostate cell lines with increasing aggressiveness. (b) miR-152 or scrambled oligonucleotides as NC (negative control) treatment of LNCaP, PC-3, MDA-PCa-2b cells resulted in decreases of DNMT1 at both RNA and protein levels. (c) Dual-luciferase assays were performed for LNCaP, PC-3, and MDA-PCa-2b cells co-transfected with the firefly luciferase constructs containing the DNMT1 wild-type or Mu 3'-UTR and miR-152 mimics or (NC) negative control. (d) siRNA-DNMT1 treatment resulted in increases in miR-152 expression in LNCaP, PC-3, and MDA-PCa-2b cells, as determined by qRT-PCR. DNMT1 expression was analyzed by immunoblots utilizing anti-DNMT1 antibody for both LNCaP, PC-3, a nd MDA-PCa-2b cells after siR-DNMT1 treatment. For all qRT-PCR experiments, expression was normalized to RNU48 (miRNA) and GAPDH (mRNA) controls. All data presented are the means of three independent experiments \pm s.e. ${ }^{*} \mathrm{P}<0.05$. 
stromal cells typically present in tissues, we utilized AA- and CA-derived cell lines derived from benign and primary tumors, along with well-established cell lines derived from metastatic PCas. Our findings derived by miRNA microarray analysis revealed a distinct miRNA expression pattern in AA-derived cell lines. qRT-PCR validation of these miRNAs showed that the five most significant miRNAs were decreased in metastatic cell lines, suggesting a role for these molecules in tumorigenesis. Since previous reports have demonstrated inheritable epigenetic changes in AA patients, we sought to determine if decreased expression was the result of DNA methylation. In silico analysis revealed that these miRNAs have dense CG regions in the promoter. Further evidence that methylation of $\mathrm{CpG}$ islands causes silencing is that each of the miRNAs, albeit to varying degrees, is re-expressed after treatment with 5-aza-2'd or TSA. To our knowledge, this is the first report that demonstrates a methylated miRNA profile that can be associated with the progression of AA prostate tumors.

Of the miRNAs influenced by 5-aza-2'd, several have been found in other tumor types, including $\mathrm{PCa}$. For example, miR-132, which targets both heparinbinding epidermal growth factor and TALIN2, is silenced by hypermethylation [15]. Of the miRNAs we assayed, miR-152 demonstrated the most significant reversal of expression, an effect consistent for both LNCaP and PC-3 cell lines. Previous reports regarding endometrial cancer [23], gastrointestinal cancer [27], and ovarian cancer [28, 29], and a report relating to PCa [30], published during the preparation of this manuscript, show that miR-152 levels are decreased in more advanced tumors. Analysis of patient data from the Taylor et al. study, deposited in the NIH-sponsored Geo database, confirms that miR-152 expression is low in the more advanced primary tumors, with the lowest expression in metastatic samples. However our analysis provides evidence that low miR-152 levels decreases probability of biochemical recurrence free survival in patients. qRT-PCR to measure normal-tumor expression ratios confirmed these findings, with $67 \%$ of patients displaying lower miR-152 expression. However, the most relevant observation is that AA patients display decreased expression of miR-152 in both uninvolved and paired tumors compared to CA patients of similar age, stage, and Gleason grade. To determine the mechanism for decreased miR-152, sodium bisulfite modification and sequencing of miR-152 promoter in aggressive PCa cell lines were performed. Both LNCaP and PC-3 cells showed $100 \%$ methylation status, highlighting that, in aggressive tumors, hypermethylation of the miR-152 promoter is a mode of silencing miR-152.

miR-152 directly targets the $3^{\prime}$ UTR of DNMT1 [23]. Across our cell line panel, DNMT1 and miR-152 showed an inverse relationship in expression. Although the miR-152/DNMT1 inverse expression relationship was significant in MDA-PCa-2b cells, both the LNCaP and PC-3 cells showed much greater miR-152/DNMT1 expression differences. However in all three cell lines, we confirmed that forced expression of miR-152 results in decreased expression of DNMT1 at both the RNA and protein levels. We also confirmed in LNCaP, PC-3, and MDA-PCa-2b cells decreased expression of several candidate targets that have been implicated in AA prostate tumors. SOS-1, which is a regulator of EGFR expression and downstream signaling, is increased in AA PCas, and most significantly decreased in the AA derived MDA-PCa$2 \mathrm{~b}$ cells [5]. Although Rictor, a subunit of the mTORC2 complex, has not been directly implicated in AA PCas, the phosphatidylinositol-3-kinase/AKT (PI3K/AKT) pathway, which is a regulator of the mTORC2 complex, has been associated with AA PCas [25]. Whereas TGF- $\alpha$ is a direct target of miR-152 in PCa cell lines [30], we observed decreased TGF- $\beta$ mRNA expression after forced miR-152 expression in all three cell lines, which further suggests that loss of miR-152 promotes increased aggressiveness through multiple signaling pathways. Previously, we have demonstrated that ABCD3 expression is associated with African American Prostate tumors [4.] Interestingly, we observed decreased ABCD3 expression in the MDA-PCa$2 \mathrm{~b}$ cells after miR-152 ectopic expression, that was not observed in LNCaP or PC-3 cells. Because DNMT1 has been characterized as one of the main enzymes responsible for maintenance of global methylation patterns in tumorrelated genes [31, 32], we investigated the role of DNMT1 on miR-152. We found that depletion of DNMT1 through SiRNA resulted in increased miR-152 in both LNCaP, $\mathrm{PC}-3$, and MDA-PCa-2b cell lines, highlighting that the effect is independent of androgen sensitivity. However, there appears to be a feed-forward loop where either loss of miR-152 and/or increased DNMT1 maintains methylation patterns, and hence miR-152 expression. miR152 is gaining interest as a factor in various tumor types; a recent report concerning nickel sulfide-transformed human bronchial epithelial (16HBE) cells demonstrated that the miRNA-152/DNMT1 relationship develops early in transformed cells [24]. Treatment of cells with 5-aza2'-d or depletion of DNMT1 led to increased miR-152 expression by reversal of promoter hypermethylation. These findings are similar to those presented here, however the available data relating to PCas suggest that the relationship between loss of miR-152 and increased DNMT1 occurs during the progression to advanced tumor status.

Our finding of a regulatory mechanism that maintains methylation patterns has implications for AA PCa patients. The fact that miR-152 expression is lower in non-malignant tissues from AA patients compared to CA non-malignant tissues suggests that miR-152 expression is regulated by inheritable differences. Although the cause of this decreased expression is still speculative, using NCBI Genome and dpSNP Database (http://www.ncbi. nlm.nih.gov/projects/SNP/snp_ref.cgi?rs=12940701), 
we did identify 38 single-nucleotide polymorphisms (SNPs) on chromosome 17q21 (46114527....46114613, complement1) region where miR-152 is located. Of these, rs200114569, which is associated with a $\mathrm{C}$ to $\mathrm{G}$ nucleotide change, and rs12940701, which is associated with a $\mathrm{C}$ to $\mathrm{T}$ change, were of interest because they may affect the methylation status of the miR-152 gene. The rs12940701 SNP has a relatively high frequency $(15 \%)$ of the minor $\mathrm{T}$ allele in the European American population $(\mathrm{n}=120)$ relative to the Yoruba (Nigerian) population $(n=118)$. Thus, the European American population could have lower methylation rates since the $\mathrm{C}$ nucleotide is changed to the $\mathrm{T}$ nucleotide, whereas, in the Yoruba population, this shift is less frequent, allowing for more $\mathrm{C}$ nucleotides, thus possibly increasing the rate of methylation. Further analysis should focus on the methylation frequency of miR-152 and on genotyping SNPs that compromise miR152 expression in AAs and CAs.

In summary, the present work highlights miR-152 as a tumor suppressor that is inactivated by methylation. Because a large number of tumor/metastasis suppressor genes are silenced as a result of methylation, miR-152 could be a central regulator of key events that contribute to tumorigenesis and aggressiveness and thus has the potential to be a therapeutic agent for PCa treatment. These results begin to unravel the molecular mechanism associated with the aggressive tumors of AA patients.

\section{MATERIALS AND METHODS}

\section{PCa cell lines and primary tissue samples}

Immortalized PCa cell lines RC-77T/E (T3c poorly differentiated primary tumor), RC-77N/E (non-malignant) were derived from AA patient as previously described [21]. RC-43T/E (T4 poorly differentiated primary tumor) and $\mathrm{RC}-43 \mathrm{~N} / \mathrm{E}$ (non-malignant) were also obtained from an AA patient (characterization unpublished). Benign cell lines derived RC-165N/hTERT (derived from AA patient) [33] and RC-170N/hTERT (derived from CA patient) [34], and primary tumor cell line RC-92a/hTERT (derived from CA patient) cells [35]. All cell lines were cultured in keratinocyte serum-free medium (KGM, LifeTechnologies, Carlsbad, CA) supplemented with bovine pituitary extract, recombinant epidermal growth factor, and 1\% penicillinstreptomycin-neomycin were maintained in KGM medium as previously described [36]. Non-malignant CA prostate epithelial cells (PrEC) were obtained from Clonetics Lonza (Switzerland) and maintained in Prostate Epithelial Cell Growth Medium (Clonetics). The CA androgenindependent and metastatic PC-3 and DU-145 PCa cell lines were maintained in Dulbecco's Modified Eagle medium (DMEM) supplemented with 10\% fetal bovine serum and $1 \%$ penicillin-streptomycin-neomycin. The CA
LNCaP and C4-2b androgen-dependent and -independent, respectively, prostate cells were maintained in T-medium. RWPE-1 normal prostate cells were maintained in KGM as previously described [37]. The malignant, androgenreceptor positive AA MDA-PCa-2b cells were purchased from ATCC (Manassas, VA). These cells were maintained in F-12K medium supplemented with $20 \%$ fetal bovine serum, $25 \mathrm{ng} / \mathrm{ml}$ cholera toxin, $10 \mathrm{ng} / \mathrm{ml}$ mouse epidermal growth factor, $5 \mu \mathrm{M}$ phosphoethanolamine, $100 \mathrm{pg} / \mathrm{ml}$ hydrocortisone, $45 \mathrm{nM}$ selenious acid, and $5 \mu \mathrm{g} / \mathrm{ml}$ bovine insulin.

\section{Patient Samples}

Patient samples were obtained from the Cooperative Human Tissue Network at the University of Alabama at Birmingham (UAB) under Institutional Review Board-approved protocols and the St. Frances Hospital and Medical Center, Hartford CT. Additionally, the Institutional Review Boards of Tuskegee University St. Frances, and UAB approved the use of tissues for this study. Tumor sections were macro dissected. There was no significant difference between the two groups with respect to tumor content. (Average percentages of tumor for AA and CA biopsies were both 54\%.) Paired normal tissues were also collected from the same patients. Altogether, samples from each of the 20 AA and 19 CA patients, along with patient-matched normal adjacent tissues, were used for qRT-PCR validation. p-values were generated using graph pad software. T-tests (the Benjamini-Hochberg corrected for multiple tests that reflects the individual patients with significant difference in mir152 expression relative to global mean of $\mathrm{u} 48$ for $\mathrm{Ct}$ values and global mean for delta $\mathrm{Ct}$ values) were performed to test for significant differences between the means, and F-tests were used to assess differences in variance between experimental groups.

\section{Quantitative Real-time PCR (qRT-PCR)}

Total RNA extraction was performed using the Ambion recover all nucleic acid isolation kit (AM 1975) modified by replacing filters with (AM10066G). RNA (10 ng) was reverse transcribed using TaqMan miRNA reverse transcription kits (Life Technologies). For mRNA expression, $1 \mu \mathrm{g}$ of total RNA was reverse transcribed using High Capacity cDNA kits (Invitrogen). Relative expression of miRNAs and mRNA was quantified with the TaqMan Universal PCR Master Mix, No AmpErase UNG, with the 7500 Fast Real-Time PCR system (Life Technologies). Thermal cycling conditions included enzyme activation for $10 \mathrm{~min}$ at $95^{\circ} \mathrm{C}, 40$ cycles of $95^{\circ} \mathrm{C}$ for $15 \mathrm{~s}$, and $60^{\circ} \mathrm{C}$ for $60 \mathrm{~s}$, according to provider's protocol. Reverse transcription for mRNA was accomplished as previously described $[22,38]$. SYBR 
Green reagents (Invitrogen) were used for quantitative real-time PCR. Thermal cycling conditions for primer sequences used for mRNA detection are included in the table below. Analyses for miRNA and mRNA were performed in triplicate. RNU48 miRNA, GAPDH, and $18 \mathrm{~S}$ ribosomal RNA were used as endogenous controls.

\section{Transfection of miRNA Precursor}

LNCaP, PC-3, and MDA-PCa-2b PCa cell lines were seeded at $2 \times 10^{5}$ cells in six-well plates on the day before transfection. Lipofectamine 2000 reagent (Life Technologies) was used to transfect $5-15 \mathrm{nmol}$ of miR152 or $5-15 \mathrm{nmol}$ of miR-Negative Control \#1 in OptiMEM (Life Technologies). Cells were harvested for assays three days after recovery in fully supplemented media, as described previously [38].

\section{Cell Proliferation Assays}

LNCaP, PC-3, and MDA-PCa-2b cells (2.5 x 102) were plated in 96-well plates in DMEM. After being cultured for $24 \mathrm{hr}$, cells were transfected with miR152 or Negative Control \#1 (Life Technologies) at a concentration of $30 \mathrm{nM}$. Cell viability was determined at 24, 48, 72, 96, and 120 days after transfection. All cells were incubated with $10 \mu \mathrm{l}$ of 3-(4,5-dimethylthiazol2-yl)-2,5-diphenyltetrazolium bromide (MTT, SigmaAldrich, St. Louis, MO) solution $(5 \mathrm{mg} / \mathrm{ml})$ in PBS for 4 hr. Dimethylsulfoxide $(50 \mu \mathrm{l})$ was added for $10 \mathrm{~min}$ after aspiration of the MTT solution. Plates were read at 560 nm.

\section{Cell Migration and Invasion assay}

Cell migration and invasion was determined using the Boyden chamber assay. Briefly, 20,000 cells were plated in the upper chamber, with or without Matrigel, containing serum-free medium containing $1 \%$ bovine serum albumin for 24 hours; this then was replaced with a serum-free medium for an additional 24 hours. The lower chamber contained medium with $10 \mathrm{ng} / \mathrm{mL}$ of epidermal growth factor was used as a chemo-attractant. The number of cells that migrated or invaded through the matrix over a 48 hour-period was determined by counting cells that stained with crystal violet on the bottom of the filter. All experiments were performed in triplicate.

\section{Sodium Bisulfite Modification and Methylation Analysis}

DNA was extracted with GenElute Mammalian Genomic DNA Miniprep kits (Sigma-Aldrich) following the manufacturer's instructions. Subsequently, bisulfite conversion of DNA $(2 \mu \mathrm{g})$ was performed with EpiTect Bisulfite kits (Qiagen, Valencia, CA). The miR-152 sequence was determined by using the UCSC Genome Browser [39]. Methylation PCR amplification primers for sequencing were designed using MethPrimer [40]. Sequence from 5' to 3' - Primer 1: GGGTTAGGGGGAGTAGTTAATTTAG and Primer 2: ATAAACTCCAAAAACATACCCATCA. qRT-PCR was performed on bisulfite-converted DNA ( $1 \mu \mathrm{l})$, using the primers described above covering two $\mathrm{CpG}$ regions upstream from the miR-152 promoter DNA sequence. A second round of amplification was performed on the first PCR amplicons and subsequently characterized by electrophoresis on $1.2 \%$ agarose gels. Sequencing of amplicons was performed at the UAB Heflin Center, Birmingham, AL. Bisulfite sequencing was analyzed by an online DNA methylation platform, Bisulfite Sequencing Data and Presentation Compilation (http://biochem.jacobsuniversity.de/BDPC/).

\section{Immunoblots}

Cells were harvested 3 days after miR-152 transfection, washed with PBS, and lysed in NP-40 lysis buffer [10 mM Tris-Cl (pH 7.4), $10 \mathrm{mM} \mathrm{NaCl}, 3 \mathrm{mM}$ $\mathrm{MgCl}_{2}, 0.5 \%$ NP-40 (Nonidet P-40), $0.15 \mathrm{mM}$ spermine, $0.5 \mathrm{mM}$ spermidine, and protease inhibitor solution] and centrifuged at $12,000 \mathrm{~g}$ for $10 \mathrm{~min}$ at $4^{\circ} \mathrm{C}$. Protein concentrations were determined with the BCA Protein Assay kit (Thermo Scientific, Rockford, IL) according to manufacturer's instructions. Protein samples were separated on 7.5\% SDS-PAGE pre-cast gels (Thermo Scientific). Protein levels were detected by anti-DNMT1, anti-mTOR, and anti-Rictor rabbit polyclonal antibodies (Cell Signaling, Danvers, MA), and analyzed by chemiluminescence.

\section{Treatment with 5-aza-2'-d}

Cells (60\% confluent) were treated with $5 \mu \mathrm{M} 5$-aza2 'd for 5 days, with fresh media supplemented with 5-aza2'd every day. Trichostatin A (TSA, a histone deacetylase inhibitor) was administered at a concentration of 100 $\mathrm{nM}$ on the last day of treatment. Cells were harvested and assayed for miR-152 expression by qRT-PCR as previously described $[21,22]$.

\section{Flow Cytometry Analysis}

Cells were harvested 3 days after miR-152 transfection, washed with cold PBS, fixed, and permeabilized with $70 \%$ cold ethanol for propidium iodide staining. Cell cycle analysis was performed with a flow cytometer (Accuri, Ann Arbor, MI). 


\section{miRNA microarray samples}

For miRNA expression profiling, 11 unique cell lines were utilized; specifically, PrEC, RC-77N/E, RC77T/E, RC-43T/E, RC-43N/E, RC-165N/hTERT, RC92a/hTERT, RC-170N/hTERT, PC-3，MDA-PCa-2b, and $\mathrm{C} 42 \mathrm{~B}$. Microarray hybridizations were performed in triplicate for each line by Ausurgen, Austin TX). In addition, primary tumor samples $(\mathrm{n}=9)$ were also processed for microarray hybridization (RC-30T, RC-33T, RC-136T, RC-139T, RC-28T, RC-78T, RC-143T, RC145T and RC-25T). Clinical characteristics are listed in (supplemental table 4). The protocols for RNA extraction and miRNA microarray hybridizations were performed by an outside vendor (Asuragen, Austin, TX).

\section{Raw data processing from microarrays}

For data processing, the bioconductor packages pipelined through R interfaces DaNTE [41] and CARMA [42] were used. Pre-processing and normalization was completed with the Affy package. Two distinct array platforms were used during the course of this project; cell lines were hybridized to one platform and primary samples were hybridized to another. The platforms differ in probe content and replication. Arrays of identical platforms were quantile normalized to minimize inter-array noise [43], using the gcRMA method [44]. Subsequently, replicates were merged into median values for statistical association analyses.

\section{Statistical analysis of normalized data}

For all analyses, $\mathrm{p}$-values $<0.05$ were considered as significant. Initial differential expression was detected using an ANOVA linear model. Of the miRNA genes that showed significant variance, we measured the specific differential expression among categorical groupings; diagnosis, pathological stage, and race. Differential expression associated with categories was measured using a moderated T-test in the limma package of $\mathrm{R}$. Cells lines representing tumor and uninvolved from the same individuals were grouped into two categories; Malignant or Non-malignant. This grouping also included established laboratory cell lines (PREC, PC3 and C42b). We incorporated multiple hypothesis testing to correct for false positive (type 1 errors) and false negative (type 2 errors). Specifically, we implemented adjusted $p$-values (Bonferroni) and false discovery rates (FDR) using the Benjamini and Hochberg method [45]. A moderate 10\% FDR cutoff was used when applicable. We also used hierarchical clustering analyses to determine groups of differentially expressed miRNAs between specific variables and to isolate specific nodes of probes that shared similar expression trends.

We used non-parametric tests when comparing across array platforms to validate the significance of specific factors in a given variable category. Specifically, a Kruskal-Walis test was used for all variables. In addition, for variables with only 2 levels, a Wilcoxon Rank Sum test was utilized for secondary validation. In cases where strict fold change values were of importance, the fold change between two factor levels was calculated using the ratio of mean expression between the variables over differences in expression between the variables. $[\log (\mathrm{x} / \mathrm{y})=\log (\mathrm{x})$ $\log (\mathrm{y})]$.

To determine the ability of significant probe profiles to differentiate samples into relevant categories, we used a partial least squares (PLS) principle component test. Specifically, once probes were found to be significantly differentially expressed, following hierarchical clustering, we identified suitable nodes or combination of probes, for each category. We determined differentially expressed probes based on diagnosis, stage and as the predictors and miRNA expression values as the response. These tests both determined whether the probes statistically associated with a specific variable or had predictive value across independent primary samples not utilized in the initial discovery ANOVA and non-parametric tests. If the largest percent variation could be explained by the variable extracted/tested, and the samples segregated according to proper category variable annotation, the probe set was considered to have significant predictive value for the specified categories. For these analyses, the DAnTE 1.2 program was utilized.

\section{Competing interests}

The authors have no conflicting financial interests.

\section{Authors' contributions}

ST and CY conceived, designed, performed the experiments, and analyzed the data. MD performed statistical analysis on microarrays and patient samples. HW, TT, and FZ performed experiments. WJ, GZ generated miRNA-mRNA binding constructs. ST, WG and CY wrote the manuscript. All authors have read and approve the manuscript in its final form.

\section{ACKNOWLEDGMENTS}

This work was supported by grants G12 RR0305921A1 (NIH/RCMI) [CY], U54 CA118623 (NIH/NCI) [CY]; and a Department of Defense Grants, PC120913, W81XWH-10-1-0543. Statistical analysis from the Geo website was performed by both the University Alabama at Birmingham and Tuskegee University Statistical Cores. We would also like to thank members of the Yates 
laboratory for their comments and discussions. We would also like to thank the Curtis D. Robinson Men's Health Institute for resources and insightful comments.

\section{REFERENCES}

1. Kheirandish $P$ and Chinegwundoh F. Ethnic differences in prostate cancer. British journal of cancer. 105(4):481-485.

2. Caso JR, Tsivian M, Mouraviev V, Polascik TJ and Moul JW. Pathological T2 sub-divisions as a prognostic factor in the biochemical recurrence of prostate cancer. BJU international. 106(11):1623-1627.

3. Powell IJ, Dyson G, Land S, Ruterbusch J, Bock CH, Lenk S, Herawi M, Everson RB, Giroux CN, Schwartz AG and Bollig-Fischer A. Genes associated with prostate cancer are differentially expressed in African American and European American men. Cancer Epidemiol Biomarkers Prev.

4. Reams RR, Kalari KR, Wang H, Odedina FT, Soliman KF and Yates C. Detecting gene-gene interactions in prostate disease in African American men. Infectious agents and cancer. 6 Suppl 2:S1.

5. Timofeeva OA, Zhang X, Ressom HW, Varghese RS, Kallakury BV, Wang K, Ji Y, Cheema A, Jung M, Brown ML, Rhim JS and Dritschilo A. Enhanced expression of SOS1 is detected in prostate cancer epithelial cells from African-American men. Int J Oncol. 2009; 35(4):751-760.

6. Reams RR, Agrawal D, Davis MB, Yoder S, Odedina FT, Kumar N, Higginbotham JM, Akinremi T, Suther S and Soliman KF. Microarray comparison of prostate tumor gene expression in African-American and Caucasian American males: a pilot project study. Infectious agents and cancer. 2009; 4 Suppl 1:S3.

7. Wallace TA, Prueitt RL, Yi M, Howe TM, Gillespie JW, Yfantis HG, Stephens RM, Caporaso NE, Loffredo CA and Ambs S. Tumor immunobiological differences in prostate cancer between African-American and European-American men. Cancer research. 2008; 68(3):927-936.

8. Kim JH, Dhanasekaran SM, Prensner JR, Cao X, Robinson D, Kalyana-Sundaram S, Huang C, Shankar S, Jing X, Iyer M, Hu M, Sam L, Grasso C, Maher CA, Palanisamy N, Mehra R, et al. Deep sequencing reveals distinct patterns of DNA methylation in prostate cancer. Genome research. 21(7):1028-1041.

9. Kobayashi Y, Absher DM, Gulzar ZG, Young SR, McKenney JK, Peehl DM, Brooks JD, Myers RM and Sherlock G. DNA methylation profiling reveals novel biomarkers and important roles for DNA methyltransferases in prostate cancer. Genome research. 21(7):1017-1027.

10. Enokida H, Shiina H, Urakami S, Igawa M, Ogishima T, Pookot D, Li LC, Tabatabai ZL, Kawahara M, Nakagawa M, Kane CJ, Carroll PR and Dahiya R. Ethnic grouprelated differences in CpG hypermethylation of the GSTP1 gene promoter among African-American, Caucasian and Asian patients with prostate cancer. Int J Cancer. 2005;
116(2):174-181

11. Kwabi-Addo B, Wang S, Chung W, Jelinek J, Patierno SR, Wang BD, Andrawis R, Lee NH, Apprey V, Issa JP and Ittmann M. Identification of differentially methylated genes in normal prostate tissues from African American and Caucasian men. Clin Cancer Res. 16(14):3539-3547.

12. Friedman RC, Farh KK, Burge CB and Bartel DP. Most mammalian mRNAs are conserved targets of microRNAs. Genome research. 2009; 19(1):92-105.

13. Lopez-Serra P and Esteller M. DNA methylation-associated silencing of tumor-suppressor microRNAs in cancer. Oncogene. 31(13):1609-1622.

14. Negrini M, Nicoloso MS and Calin GA. MicroRNAs and cancer--new paradigms in molecular oncology. Current opinion in cell biology. 2009; 21(3):470-479.

15. Formosa A, Lena AM, Markert EK, Cortelli S, Miano R, Mauriello A, Croce N, Vandesompele J, Mestdagh P, Finazzi-Agro E, Levine AJ, Melino G, Bernardini S and Candi E. DNA methylation silences miR-132 in prostate cancer. Oncogene. 32(1):127-134.

16. Suh SO, Chen Y, Zaman MS, Hirata H, Yamamura S, Shahryari V, Liu J, Tabatabai ZL, Kakar S, Deng G, Tanaka Y and Dahiya R. MicroRNA-145 is regulated by DNA methylation and p53 gene mutation in prostate cancer. Carcinogenesis. 32(5):772-778.

17. Lodygin D, Tarasov V, Epanchintsev A, Berking C, Knyazeva T, Korner H, Knyazev $\mathrm{P}$, Diebold $\mathrm{J}$ and Hermeking $\mathrm{H}$. Inactivation of miR-34a by aberrant $\mathrm{CpG}$ methylation in multiple types of cancer. Cell cycle (Georgetown, Tex. 2008; 7(16):2591-2600.

18. Jones J, Grizzle W, Wang H and Yates C. MicroRNAs that affect prostate cancer: emphasis on prostate cancer in African Americans. Biotech Histochem.

19. White NM, Youssef YM, Fendler A, Stephan C, Jung K and Yousef GM. The miRNA-kallikrein axis of interaction: a new dimension in the pathogenesis of prostate cancer. Biological chemistry. 393(5):379-389.

20. Brase JC, Johannes M, Schlomm T, Falth M, Haese A, Steuber T, Beissbarth T, Kuner R and Sultmann H. Circulating miRNAs are correlated with tumor progression in prostate cancer. International journal of cancer. 128(3):608-616.

21. Theodore S, Sharp S, Zhou J, Turner T, Li H, Miki J, Ji Y, Patel V, Yates C and Rhim JS. Establishment and characterization of a pair of non-malignant and malignant tumor derived cell lines from an African American prostate cancer patient. Int J Oncol. 37(6):1477-1482.

22. Theodore SC, Rhim JS, Turner T and Yates C. MiRNA 26a expression in a novel panel of African American prostate cancer cell lines. Ethn Dis. 20(1 Suppl 1):S1-96-100.

23. Tsuruta T, Kozaki K, Uesugi A, Furuta M, Hirasawa A, Imoto I, Susumu N, Aoki D and Inazawa J. miR-152 is a tumor suppressor microRNA that is silenced by DNA hypermethylation in endometrial cancer. Cancer research. 
71(20):6450-6462.

24. Ji W, Yang L, Yuan J, Yang L, Zhang M, Qi D, Duan X, Xuan A, Zhang W, Lu J, Zhuang Z and Zeng G. MicroRNA-152 targets DNA methyltransferase 1 in NiS-transformed cells via a feedback mechanism. Carcinogenesis. 34(2):446-453.

25. Wang BD, Yang Q, Ceniccola K, Bianco F, Andrawis R, Jarrett T, Frazier H, Patierno SR and Lee NH. Androgen receptor-target genes in african american prostate cancer disparities. Prostate cancer. 2013:763569.

26. Jones J, Grizzle W, Wang H and Yates C. MicroRNAs that affect prostate cancer: emphasis on prostate cancer in African Americans. Biotech Histochem. 2013; (2013 The Biological Stain Commission):1-15.

27. Chen Y, Song Y, Wang Z, Yue Z, Xu H, Xing C and Liu Z. Altered expression of MiR-148a and MiR-152 in gastrointestinal cancers and its clinical significance. J Gastrointest Surg. 14(7):1170-1179.

28. Xiang Y, Ma N, Wang D, Zhang Y, Zhou J, Wu G, Zhao R, Huang H, Wang X, Qiao Y, Li F, Han D, Wang L, Zhang G and Gao X. MiR-152 and miR-185 co-contribute to ovarian cancer cells cisplatin sensitivity by targeting DNMT1 directly: a novel epigenetic therapy independent of decitabine. Oncogene.

29. Zhou X, Zhao F, Wang ZN, Song YX, Chang H, Chiang Y and $\mathrm{Xu} \mathrm{HM}$. Altered expression of miR-152 and miR-148a in ovarian cancer is related to cell proliferation. Oncology reports. 27(2):447-454.

30. Zhu C, Li J, Ding Q, Cheng G, Zhou H, Tao L, Cai H, Li P, Cao Q, Ju X, Meng X, Qin C, Hua L, Shao P and Yin C. miR-152 controls migration and invasive potential by targeting TGFalpha in prostate cancer cell lines. The Prostate.

31. Gravina GL, Ranieri G, Muzi P, Marampon F, Mancini A, Di Pasquale B, Di Clemente L, Dolo V, D'Alessandro $\mathrm{AM}$ and Festuccia $\mathrm{C}$. Increased levels of DNA methyltransferases are associated with the tumorigenic capacity of prostate cancer cells. Oncology reports. 29(3):1189-1195.

32. Yaqinuddin A, Qureshi SA, Qazi R, Farooq S and Abbas F. DNMT1 silencing affects locus specific DNA methylation and increases prostate cancer derived PC 3 cell invasiveness. The Journal of urology. 2009; 182(2):756-761.

33. Gu Y, Kim KH, Ko D, Srivastava S, Moul JW, McLeod DG and Rhim JS. Androgen and androgen receptor antagonist responsive primary African-American benign prostate epithelial cell line. Anticancer research. 2005; 25(1A):1-8.

34. Li H, Zhou J, Miki J, Furusato B, Gu Y, Srivastava S, McLeod DG, Vogel JC and Rhim JS. Telomeraseimmortalized non-malignant human prostate epithelial cells retain the properties of multipotent stem cells. Experimental cell research. 2008; 314(1):92-102.

35. Miki J, Furusato B, Li H, Gu Y, Takahashi H, Egawa S, Sesterhenn IA, McLeod DG, Srivastava S and Rhim JS.
Identification of putative stem cell markers, CD133 and CXCR4, in hTERT-immortalized primary nonmalignant and malignant tumor-derived human prostate epithelial cell lines and in prostate cancer specimens. Cancer research. 2007; 67(7):3153-3161.

36. Gu Y, Kim KH, Ko D, Nakamura K, Yasunaga Y, Moul JW, Srivastava S, Arnstein P and Rhim JS. A telomeraseimmortalized primary human prostate cancer clonal cell line with neoplastic phenotypes. International journal of oncology. 2004; 25(4):1057-1064.

37. Bello D, Webber MM, Kleinman HK, Wartinger DD and Rhim JS. Androgen responsive adult human prostatic epithelial cell lines immortalized by human papillomavirus 18. Carcinogenesis. 1997; 18(6):1215-1223.

38. Jones J, Wang H, Zhou J, Hardy S, Turner T, Austin D, He Q, Wells A, Grizzle WE and Yates C. Nuclear Kaiso indicates aggressive prostate cancers and promotes migration and invasiveness of prostate cancer cells. The American journal of pathology. 181(5):1836-1846.

39. Kent WJ, Sugnet CW, Furey TS, Roskin KM, Pringle TH, Zahler AM and Haussler D. The human genome browser at UCSC. Genome research. 2002; 12(6):996-1006.

40. Li LC and Dahiya R. MethPrimer: designing primers for methylation PCRs. Bioinformatics (Oxford, England). 2002; 18(11):1427-1431.

41. Polpitiya AD, Qian WJ, Jaitly N, Petyuk VA, Adkins JN, Camp DG, 2nd, Anderson GA and Smith RD. DAnTE: a statistical tool for quantitative analysis of -omics data. Bioinformatics (Oxford, England). 2008; 24(13):15561558.

42. Greer KA, McReynolds MR, Brooks HL and Hoying JB. CARMA: A platform for analyzing microarray datasets that incorporate replicate measures. BMC bioinformatics. 2006; $7: 149$.

43. Smyth GK and Speed T. Normalization of cDNA microarray data. Methods (San Diego, Calif. 2003; 31(4):265-273.

44. Hsieh WP, Chu TM, Lin YM and Wolfinger RD. Kernel density weighted loess normalization improves the performance of detection within asymmetrical data. BMC bioinformatics. 12:222.

45. Benjamini Y, Drai D, Elmer G, Kafkafi N and Golani I. Controlling the false discovery rate in behavior genetics research. Behavioural brain research. 2001; 125(1-2):279284. 